\title{
Transformation of Teachers to Mentors: Prerequisite of Time is to Excel Innovative Practices in Academics
}

\author{
Neelesh Malviyaa ${ }^{1, \star}$, Sapna Malviya², Rajiv Saxena ${ }^{1}$, Manisha Dhere ${ }^{1}$ \\ ${ }^{1}$ Smriti College of Pharmaceutical Education, Indore, Madhya Pradesh, INDIA. \\ ${ }^{2}$ Modern Institute of Pharmaceutical Sciences, Indore, Madhya Pradesh, INDIA.
}

\begin{abstract}
The perception of Mentoring is definitely not new; indeed, it comes from a character named "Mentor" in Homer's Odyssey. He was a trusted mentor to Odysseus' son. The recent studies and Figures have given rise to prosperous mentoring. Mentoring focuses on the individual's needs, his role is to inculcate and instill skills needed for future roles. Mentors have often had a successful career path, beginning in a similar place as the mentee. They offer assistance through sharing their own experiences, providing valuable feedback and giving the mentee access to their personal network. The technology approaches of teaching and learning are coupled with new techniques viz Case Studies, Student Centered learning, Outcome based learning and problem based learning. Aforesaid approaches are emerged recently and verified to have constructive impact on learning of an individual. Those were the good olden days wherein Professors of the institutes were standing and delivering lecturers via one-way communication, students are listening continuously and preparing their notes, these days are now over and substituted with more innovative and creative ways of facilitating, sharing and disseminating knowledge among the students. The present article summarizes current need of mentors to inculcate skills, nurture talent and build prosperous career of young budding professionals. The highlights of the contents are recent trends of innovative teaching pedagogy to facilitate new breeds and stages of mentoring and its significance in the nation development.
\end{abstract}

Key words: Mentor, Teacher, Skills, Teaching pedagogy, Innovation, Knowledge.

\section{INTRODUCTION}

The strategy of educational programs is continuously directed by beliefs about in what way scholars learn in an academic discipline. Whether explicit or implicit, these techniques impact what students in a course will be taught, how they will be taught, and how their learning will be verified. Thus the seven principles of Learning with Understanding are principled Conceptual Knowledge, that is learning with understanding is facilitated when new and existing knowledge is structured around the major concepts and principles of the discipline, Prior Knowledge that is Learners use what they already know to construct new understandings, Meta cognition that is Learning is facilitated through the use of meta cognitive strategies that identify, monitor, and regulate cognitive processes, Differences among learners that is learners have different strategies, approaches, patterns of abilities, and learning styles that are a function of the interaction between their heredity and their prior experiences. ${ }^{1}$ Motivation that is a learner's inspiration to learn and sense of nature affects what is learned and understand, how much is learned, and how much or at what extent dedication will be put into the learning process and Situated Learning means continuous practices and activities in which people engage while learning to shape what is learned. Their usefulness lies in the guidance they provide for the design of curriculum, instruction, assessment, and professional development for advanced study that fosters in students a deep
Submission Date: 10-02-2021; Revision Date: 24-03-2021; Accepted Date: 12-04-2021

DOI: 10.5530/ijper.55.2s.108 Correspondence: Dr. Neelesh Malviya Principal and Professor, Smriti College of

Pharmaceutical Education, Indore-452010

Madhya Pradesh, INDIA.

Phone no: +91-9826319555

Email id: nil30oct@gmail.com

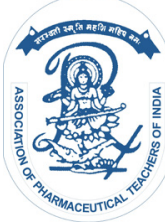

www.ijper.org 


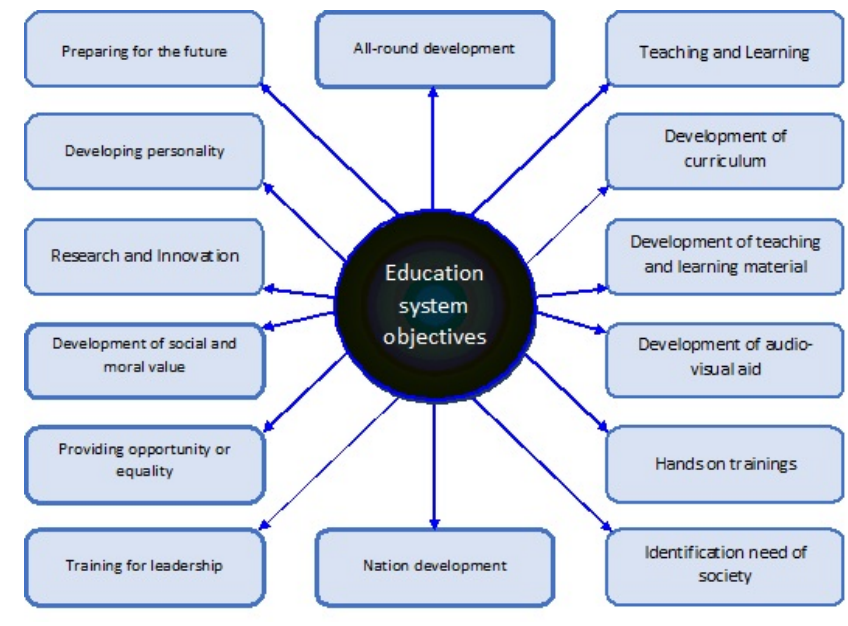

Figure 1: Education system objectives.

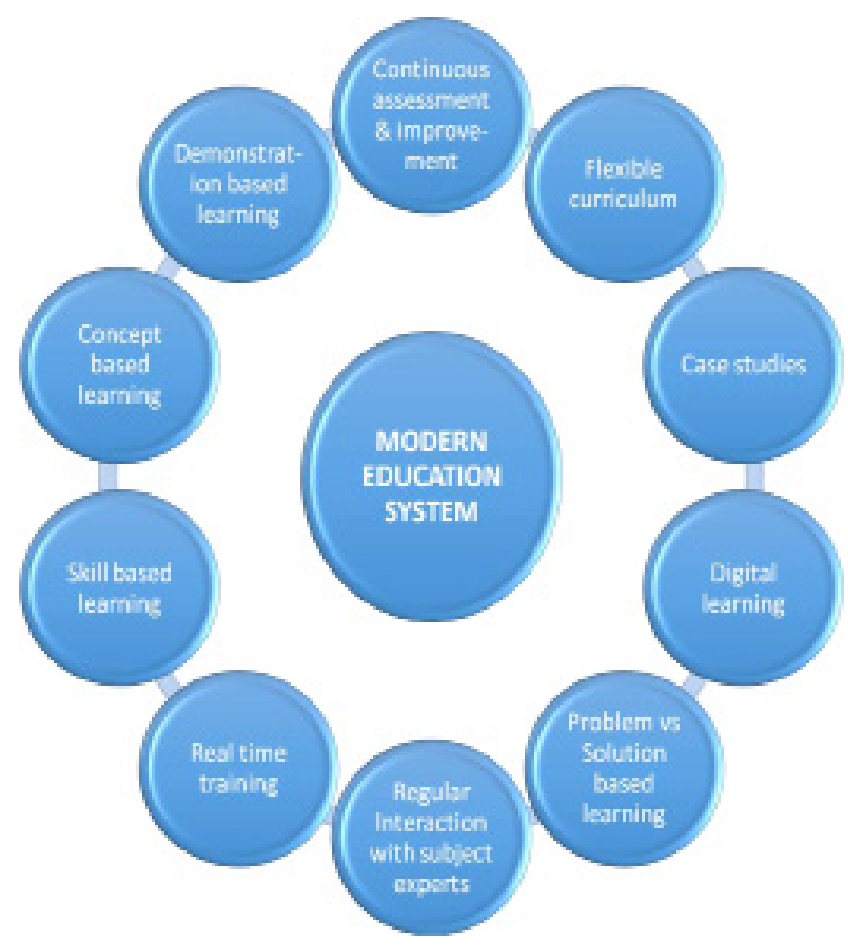

Figure 2: Modern education system.

conceptual understanding of a domain (Figure 1). The mentors should focus on Performance, Employability, Skill building, improving proficiency, Motivation, Involvement, Collective Learning, Value addition, Ensuring Transparency, Recognition and Information dissemination among young budding. ${ }^{2}$

\section{SCULPT OF MODERN EDUCATION SYSTEM}

The modern educational system (Figure 2) should be practiced and followed by the concept of Teach the Teacher due to fulfill the needs of current generation to make it much smarter, The Teacher is facing real time challenge to be engaged and engrossed in discussions in classroom and continuously involve and assimilate the concepts, ideas, learning and development. The students should be given an opportunity to teach in classrooms so the orientation of students expands and they understand the concept in better way and it stays long in their minds. The faculty should be familiarized with cooperate culture such as language, working style and pattern. The culture of corporate, various lessons and concept should develop and share with the students. ${ }^{3}$ The team building exercises also play major role to motivate students by enhancing their creativity through problem solving skills. By such practices of team building via activities make students capable to share their conclusions and outcomes with others and results are accomplished with pride and process becomes constructive. Another approach is $\mathrm{Z}$ to $\mathrm{A}$ approach which is working backwards attempts to explain application first and then the concept. Personalized reflection about an experience and applying learning to arrive at the concept is the core of this best practice. From early stages of childhood, the teachers are practicing the technique of revising Lesson learnt a day before. This practice is considered to provide good results. Although some techniques are adopted in olden times which exist till know that we share experiences, understandings and our continuity via mode of stories. Creation of ideas and use of visual aids helps to retain in our memory. The learning process is enhanced by the brain storming. This is a process of linking the ideas with the main theme. ${ }^{4}$

The present world deals with the variety of technology, use of computers, projectors, internet facilities and many more. Every component of life is explored by the use of technology. The Internet encompasses the detailed information of new innovations and discoveries. Rightly stated through Aristotle, "training is an honor in prosperity and a refugee in adversity." is what all of us feels now. The various technology which are currently used inside the Lecture halls are Computer/Laptops inside the classes or in study rooms which allows the trainer to spectacle a new lesson, show illustrations and display valuable information's on websites. The very good concept originated is to allow students to maintain blogs which includes thoughts, ideas and assignments which provides remark and reflection of the scholar. Wikipedia, an online encyclopedia is additional group focused to permit more than one members of the organization to edit a single document and create an actually collaborative and punctiliously edited completed product. $^{5}$

An interactive whiteboard which gives touch control of computer applications enhances the understanding 
inside the study room with the support of showing anything that may be on a PC screen. However, it's miles interactive so the scholars can draw, write, or manipulate photographs on the interactive whiteboard. ${ }^{6}$

Another technology is the digital video allows students to get admission to videos immediately with the aid of no longer making use of the general public net. The study tools which are available online encourage students and increase its involvement. ${ }^{5}$

\section{OVERALL VISION OF TWENTY-FIRST CENTURY PEDAGOGY}

Pedagogy is the art and science of teaching. Teachers have various strategies of teaching but there is no single approach which suits in all conditions. The learning and its outcomes can be achieved by different strategies used in different combinations with different groups of students. The strategies depend on background of students, their learning abilities and styles. So, the pedagogy contains array of teaching strategies that provides and support intellectual involvement, attachment tothewiderworld. The supportiveclassroomenvironments and recognition of difference should be implemented across all key learning, and subject areas. This practice is effective in promoting wellbeing of teachers, students and community, enhances and builds confidence. The analysis of the pedagogy is done via pedagogical analysis stands for analysis based on pedagogy. ${ }^{7}$ The teaching content is divided in to various subunits, topics or may be in the form of single concept during the process of analysis. The pedagogical analysis step includes the division of the teaching contents related to a particular unit into various sub-units. The sub units are further arranged in the form of number of periods required. Further the quintessence of the teaching content related to the subunit is briefly written. Along with this proper writing of suitable knowledge related to its past, instructional objectives also need to be incorporated. The selection of appropriate teaching strategies for the subunit is done as per the following instructions. 1. First of all write the name of the methods that are applied. 2. The indication of the teaching aids is necessary. 3. Illustration of required demonstration and experimentation needed must also be mentioned in brief. 4. Indication of the required board work is also required. 5. Mentioning of the probing questions which are linked to the sub-unit along with the appropriate answers has to be done. 6. At the end reparation of work sheet related to the sub unit along with providing suitable examples, illustration or analogies and table of specification for the sub-unit is necessary. The teaching pedagogy has two main objectives foremost is smooth conduction of teaching and second one is to obtain maximum output for better teaching outcomes. In this method discipline of education or pedagogy promotes an entire mutual associations and interdependence between the succeeding four supports of the teaching learning process for achieving finest probable consequences in the task of teaching i.e. effective teaching. ${ }^{8}$

\section{FUNCTIONS OF MENTORS AND STAGES OF MENTORING}

The term mentee is the broad range of individuals who may be in the role of "learner" in mentoring relationships, regardless of the age or position of the mentor and mentee. An individual who utilizes his expertise to develop the career of a mentee is known as mentor. The mentor basically fulfills two requirements of mentee first is to provide advice to establish his career and to enhance professional performance. Indeed, he is the role model and supporter and his roles provide mentee explicit and implicit lessons associated to professional development (Figure 3). ${ }^{9}$

Additionally, mentored personnel's have good performances, acquire high salaries and good career opportunities as compared to non-mentored personnel's. The mentor plays a major rolein developingleaders of next generation, learners of new technology and reenergizing career. The various stages of mentoring start with informal mentoring which happens professional or social interactions between potential mentors and mentees. Both the parties are in search of optimistic, pleasant association that would explain the spare time and effort required in mentoring. Formal mentoring programs includes development of demographic variables as well as common professional interests. The good mentoring via formal program requires exploring the association and appraising the suitability of the mentor-mentee match. The process turns into cultivation stage which is primary stage of Learning and development. This stage is the Learning stage. This leads to functions related to their career in which mentor train and coach mentee to work effectively and efficiently. This training includes challenging assignments to the mentee to make best use of their exposure and impression in their professional career.

Mentors are those guides who provide valued guidance and advice to mentee's to survive in this competitive world. The interpersonal bond and association between both the parties confirms their professional identity. The stage of cultivation is commonly positive for both mentor as well as the mentee. 


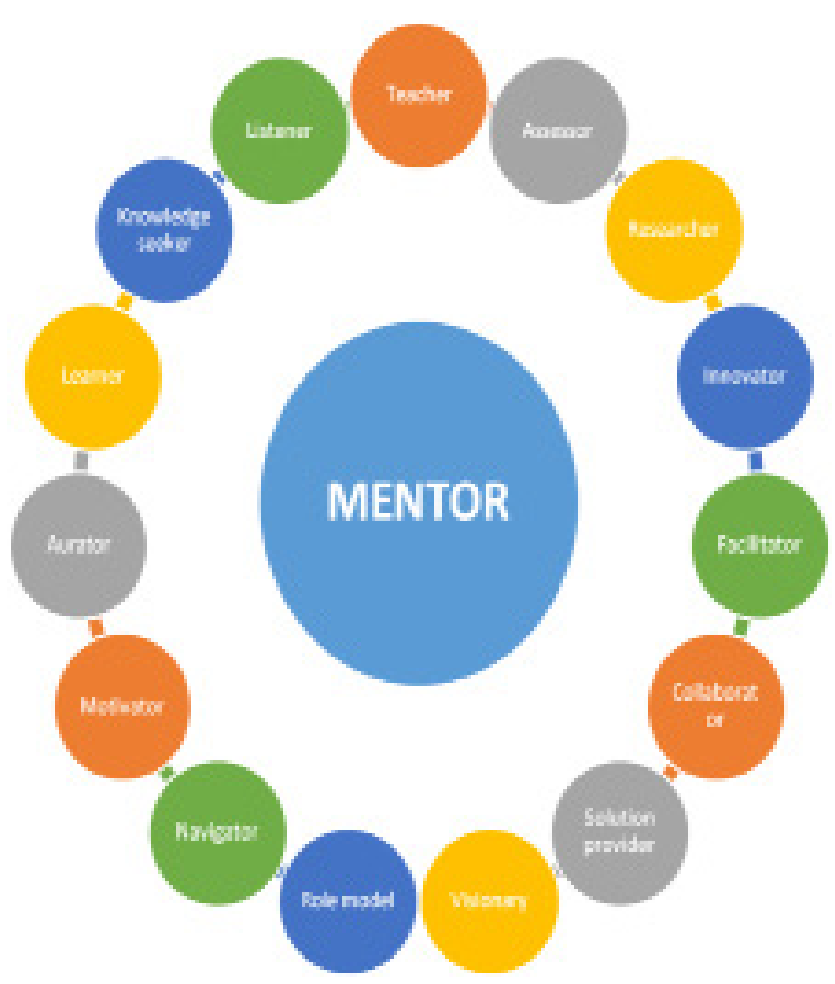

Figure 3: Functions of mentors.

The stage of separation commonly illustrates the end of a mentoring relationship. No further things are left to be learned. The mentee might wish to create an independent identity. Otherwise the mentor may send the mentee off in a similar way parent sends off an adult child. ${ }^{10}$

\section{MENTORING OF TEACHER'S TO IMPART QUALITY EDUCATION AND OVERALL DEVELOPMENT OF STUDENTS}

Mentoring Beginner teachers plays a pivotal role in professionaldevelopment,performanceandimprovement on the whole. Mentors have good pedagogical skills, interpersonal skills, capabilities to convey coaching and instructions, deeper understanding of development of teachers as well as students and effective communication skills. In current scenario mentoring is included in induction for beginner teachers. Mentoring is the powerful tool and recognized very well by the today's society. Mentors are guide and supporter for beginner teachers and they provide cognitive coaching, enhancing their skills to understand culture of student and their family, upliftment of their morale for teaching profession. Researchers identified that the beginner teachers found the process of mentoring and coaching to have beneficial especially in the early years of teaching. It provides adequate support, inspiration, positive deliberations, constant supervision as well as well-matched mentor opportunities. Mentors claimed that the mentoring to beginner teachers can be very effective, if mentors had adequate time along with administrative support, more meetings with mentee, attention in mentoring and provided with mentoring skills. ${ }^{11}$

\section{MENTORS-ROLE MODEL FOR STUDENTS}

Mentors are wise and trusted counselor, in this current scenario the mentoring has found applications in every forum of learning. In academics, mentor is often used synonymously with faculty adviser. The mentors are guide, coach and "go to" personnel from where you can ask questions or doubts. A role model is someone you look up to. Someone you try to emulate. When you look at that person, you say to yourself, "That is what I want to be" or "He/she is what I want my future to look like". The mentor enlightens the students and demonstrates the researchers and students to assess journal and articles, inscribe manuscripts and revise them if needed, Train them to manage time and supervise personnel, motivate them to be leaders and to come in front, teach mentee to conceptualize a study, collect relevant data, to analyze and interpret, provides consistent career development opportunities to aid in the exchange of ideas, teach them to analyses their Reviews and Research. Teach them techniques of scheduling their routines, structure their meetings, valuable directions about career and work, Helps them mentee improve teaching skills, Shows the mentee how to plan for and ensure research productivity, Assists the mentee in writing grant applications, encourages strategic thinking and gives timely feedback on the mentee's work. ${ }^{12}$

\section{MENTORING AS INVESTMENT FOR NATIONAL DEVELOPMENT}

Mentoring is an influential tool that certainly marks the lives. ${ }^{13,14}$ Investigation determines that mentoring has the power to improve their lives and productivity. The young professionals who take part in mentoring establish better performance, more prone to have good education, and a healthier attitude towards life than non-mentored youth. ${ }^{15}$

Furthermore, studies of mentoring courses expresses that mentoring associations decreases adverse youth activities and show promise in preventing substance abuse. Mentoring offers the capacity to build proactive tendencies. It includes fundamentals of optimistic youth development philosophy, helping to build, shape assets and fostering resiliency. ${ }^{16}$ Contribution in mentoring reinforces positive social attitudes and peer relationships, and mentoring relationships have more trusting relation- 
ships and better communication with their parents. This enhances the chance for appropriate use of time, positive self-expression along with civic engagement and educational achievement. All these factors allow them in order to reach their potential. ${ }^{17}$

\section{CONCLUSION}

The above manuscript concludes that transformation of teachers to mentors is prerequisite of time is to excel innovative practices in academics. The need of mentor's is growing tremendously due to fact they employ such tools which make professional more engaging, more self-motivated, energetic, more achieving and even richer. These mentors understand the potential of technology and offer customized professional education offerings that we empower teachers to use expertise to help improve student learning. Learning via professional techniques is fundamental in mastering challenges, becoming opportunistic and improvements in student learning. Such learning's are fruitful to empower, developing competence and confidence with new models of skill enhancement, make professionals to target and achieve their goals, groom them with $21^{\text {st }}$ century education and ensure and gain technology investments.

\section{CONFLICT OF INTEREST}

The authors declare that there is no conflict of interest.

\section{REFERENCES}

1. Bidabadi NS, Isfahani AN, Rouhollahi A, Khalili R. Effective Teaching Methods in Higher Education: Requirements and Barriers. J Adv Med Educ Prof. 2016;4(4):170-8.

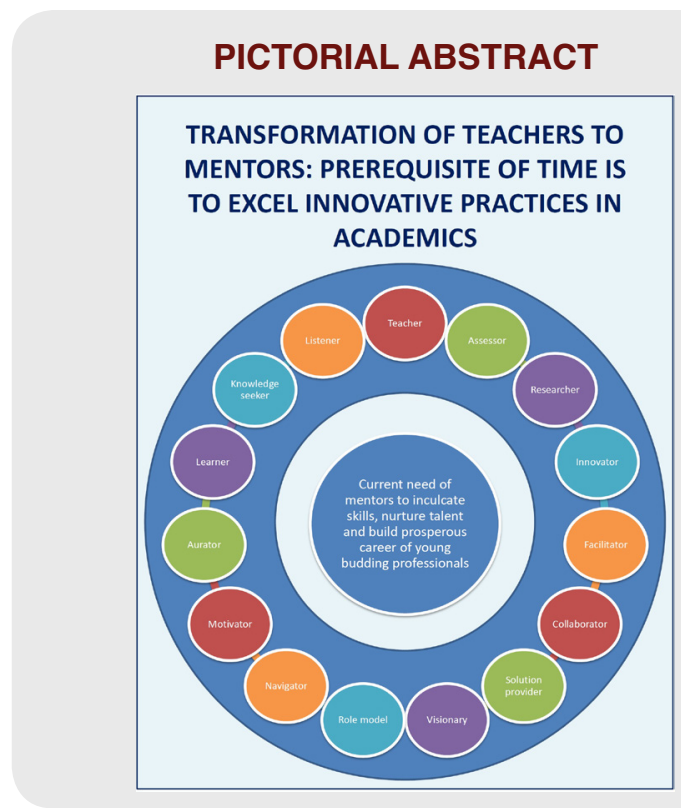

2. Brown HD. Principles of Language Learning and Teaching. $5^{\text {th }}$ ed. New York: Pearson Education; 2007.

3. Clement R. Ethnicity, contact and communicative competence in a second language. Language: Social psychological perspective. Oxford: Pergamon; 1980;147-54.

4. Dornyei Z. Creating a Motivating Classroom Environment. International Handbook of English Language Teaching. New York: Springer; 2007;719-31.

5. Akkoyunlua B, Erkanb S. Study on student and teacher views on technology use, $13^{\text {th }}$ International Educational Technology Conference, Procedia-Social and Behavioral Sciences. 2013;103:68-76.

6. Türel YK. Developing Teachers' Utilization of Interactive Whiteboards. Proceedings of Society for Information Technology and Teacher Education International Conference 2010, Chesapeake, VA: AACE; 2010;3049-54.

7. Wall $\mathrm{K}$, Higgins $\mathrm{S}$, Smith $\mathrm{H}$. The visual helps me understand the complicated things: Pupil Views of Teaching and Learning with Interactive Whiteboards. British Journal of Educational Technology. 2005;36(5):851-67.

8. Bhowmik M, Banerjee B, Banerjee J. Role of Pedagogy in Effective Teaching. Basic Research Journal of Education Research and Review. 2013;2(1):1-5.

9. Lovat TJ. The Role of the 'Teacher' coming of Age?. Australian Council Deans of Education, Discussion Paper; 2003.

10. Daniel JH. Introduction to Mentoring, a Guide for Mentors and Mentees, Centering On Mentoring 2006 Presidential Task Force American Psychological Association; 2006.

11. Vikaraman SS, Mansor AN, Izham M, Hamzah M. Mentoring and Coaching Practices for Beginner Teachers-A Need for Mentor Coaching Skills Training and Principal's Support. Creative Education. 2017;8(1):156-69.

12. Veenman S. Perceived Problems of Beginner Teachers. Review of Educational Research. 1984;54(2):143-78.

13. Sweeney BW. Leading the Teacher Induction and Mentoring Programme. Arlington Heights, IL: Sky Light Training and Publishing Inc; 2011.

14. Malviya N, Malviya S. Academia-industry collaboration: A driving force for accelerating pharma research. Pharma Times. 2018;50(05):25-8.

15. Law N, Yuen A, Fox B. Educational innovations beyond technology: Nurturing Leadership and Establishing Learning Organisations. Springer, New York; 2011.

16. Law N, Punie KY. Multiple pathways to enhance multilevel learning for scaling up systemic ICT-enabled learning innovations: Lessons from 7 European and Asian cases. Scaling Educational Innovations, spring, Singapore. 2015;197-223.

17. Law N, Pelgrum WJ, Plomp T. Pedagogy and ICT in schools around the World: Findings from the SITES 2006 Study. CERC and Springer, Hong Kong; 2008. 


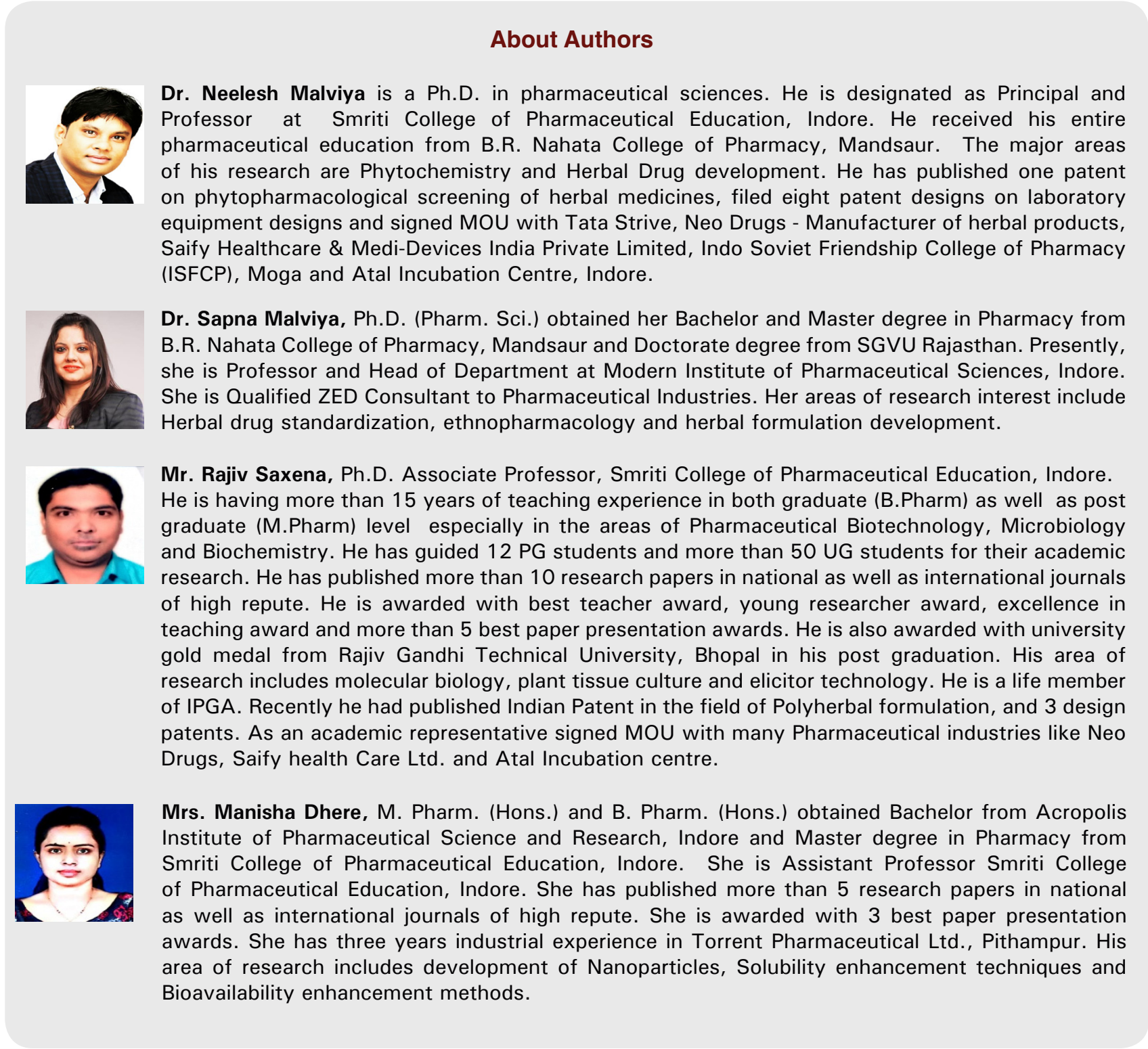

Cite this article: Malviya N. Transformation of Teachers to Mentors: Prerequisite of Time is to Excel Innovative Practices in Academics. Indian J of Pharmaceutical Education and Research. 2021;55(2s):s373-s378. 